\title{
Advancing the national and global knowledge economy: The role of research universities in developing countries
}

\author{
Author: Philip G. Altbach
}

Persistent link: http://hdl.handle.net/2345/bc-ir:103804

This work is posted on eScholarship@BC, Boston College University Libraries.

Post-print version of an article published in Studies in Higher Education 38(3): 316-330. doi:10.1080/03075079.2013.773222.

These materials are made available for use in research, teaching and private study, pursuant to U.S. Copyright Law. The user must assume full responsibility for any use of the materials, including but not limited to, infringement of copyright and publication rights of reproduced materials. Any materials used for academic research or otherwise should be fully credited with the source. The publisher or original authors may retain copyright to the materials. 
Rev 11-26-12

\title{
Advancing the National and Global Knowledge Economy: The Role of Research Universities in Developing Countries
}

\author{
PHILIP G. ALTBACH
}

Research universities are at the center of the global knowledge economy - and at the pinnacle of the national higher education system. They are the institutions that appear in the global rankings-and thus the most visible academic universities (Hazelkorn 2011). Research universities play a complex set of roles in the academic system (Altbach 2009). These include, of course, the core missions relating to production of research and to the training of students to engage in research-thus an emphasis on postbaccalaureate education. The research university is no ivory tower and is relevant to the wider community; much of its research is carried out in collaboration with funding and sponsorship from nonuniversity sources. The research university is a highly complex and multifaceted institution, serving many societal roles (Altbach 2007a).

Research universities worldwide have a great deal in common-stemming from a specific tradition and serving similar roles. Mohrman, Ma, and Baker (2008) have signified an emerging global model of the research university, with common characteristics. But there are also significant national variations (Altbach 2011). This essay focused especially on research universities in developing and middle-income countries. They have especially crucial roles in 
the development of differentiated and effective academic systems-indeed, in making it possible for their countries to join the global knowledge society and to compete effectively in the sophisticated knowledge economies of the 21st century.

Research universities are defined here as academic institutions committed to the creation and dissemination of knowledge, in a range of disciplines and fields, and featuring the appropriate laboratories, libraries, and other infrastructures that permit teaching and research at the highest possible level. While typically large and multifaceted, some research universities may be smaller institutions, concentrating on a narrower range of subjects. Research universities educate students, usually at all degree levels -an indication the focus extends beyond research. Indeed, this synergy of research and teaching is a hallmark of these institutions, which employ mainly full-time academics holding doctoral degrees (Kerr 2001).

Motivating this discussion is a conviction that knowledge production and dissemination must spread internationally and that all regions of the world need a role in the knowledge network (Altbach 1987). While all regions may include centers and peripheries-the centers mainly concentrated in the major industrialized countries for the foreseeable future-there is room, indeed a necessity, for a wider dissemination of research capacity throughout the world. It may not be possible for each country to have a research university, but many developing and middle-income countries can develop universities with research capacity and the ability to participate in the world knowledge system. Smaller 
countries can form regional academic alliances, to build enough strength in selected fields for promoting participation in global science.

The argument can be made that all countries need academic institutions, linked to the global academic system of science and scholarship, so that they can understand advanced scientific developments and participate selectively in global science. Academic institutions in small or poor countries cannot compete with the Oxfords or Harvards of the industrialized nations. But most countries can support at least one university of sufficient quality, to participate in international discussions of science and scholarship and undertake research in one or more fields relevant to national development.

Research universities generate growing enthusiasm worldwide. Countries come to the conclusion that such institutions are the key to gaining entry into the knowledge economy of the 21st century. Not only do these institutions train key personnel, but they form windows to scientific information worldwide by providing opportunities for top-level scientific communication. Faculty members and students at these institutions connect with colleagues everywhere and participate in global science and scholarship. Even in the United States and the United Kingdom, concern is rising about maintaining the standards of existing research universities (Rhoten and Calhoun 2011). Germany worries about the international competitiveness of its top universities and has allocated resources to some key institutions, while the Japanese government has funded competitive grants to create "centers of excellence." China has placed emphasis on creating 
"world-class" research universities, and India is finally beginning to think about the quality of its mainstream institutions. Similar programs to enhance standards exist in South Korea, Chile, Taiwan, and elsewhere. Several of Africa's traditionally strong universities are seeking to improve their quality in an effort to achieve research university status, with assistance from external funders; but this process is, in general, behind levels of academic development in the other continents.

In keeping with the rising profile of research universities in developing countries, many national policymakers, analysts of higher education, and even the international aid agencies and the World Bank previously were convinced that only basic education was worth supporting and now understand that research universities are important for national development. Research universities have emerged on the policy agenda in many developing countries, especially larger nations that seek to compete in the global knowledge economy.

While the research universities of the developing world have not yet achieved the top levels of the global rankings, they are nonetheless extraordinarily important within their countries and regions; and they are steadily improving their global reputations and their competitiveness on the international stage. While they may still be largely peripheral to the top universities in North America and Europe, they are centers within their countries and regions (Altbach 2009). Without question, the trajectory of the research universities in key developing regions is upward; and with time and continued 
support and emphasis, they will join the top ranks. A key point is that research universities around the world are part of an active community of institutions that share values, foci, and mission.

\section{RESEARCH UNIVERSITIES AND THE ACADEMIC SYSTEM}

Research universities, especially in developing countries, constitute a very small part of the entire academic environment. Even in major developed countries, such as the United States, there are perhaps 220 research universities, in an academic system of more than 4,000 postsecondary institutions. In the United Kingdom, the Russell Group of research university includes just 25 of the country's 100 universities and 300 postsecondary institutions. Smaller developing countries have perhaps one research university, and many have none. Large countries, such as China, are developing approximately 100 research universities as part of the 985 and 211 Projects to build world-class institutionsout of more than 3,000 academic institutions nationwide.

Research universities are a small, specialized, but centrally important part of any academic system. While every country has a de facto academic system, many have not formally organized a system; and thus the research universities are not appropriately defined and generally inadequately supported. A clearly differentiated academic system is necessary, if research universities are to flourish. Perhaps the best example of such a system is the well-known California public higher education system. The California Master Plan established the three- 
tiered California public higher education system-with three systems clearly differentiated by function but linked through system articulation. This arrangement has successfully operated for more than a half century. At the pinnacle of the system are the 10 campuses of the University of California. These universities, led by the Berkeley campus, admit the top eighth of high school students in the state and have a research mission. The next level consists of the 23-campus California State University system, which enrolls around 433,000 students. These institutions offer bachelor's and master's degrees, but not doctorates; and the academic staff are not expected to maintain a research intensity, on par with the academics in the University of California system. The community college system has 112 campuses, with 3 million students - the largest such system in the United States; these are all colleges with teaching and service at their core and with limited research capacity. Funding patterns, missions, and governance all differ among the three tiers of the California system, and state regulation has maintained the different missions of the public colleges and universities. The Master Plan imposed differentiation across California public higher education and remains a defining and effective innovation that has served the state well over more than a half century. By distributing resources with an ideal of efficiency at its core, the Master Plan also institutionalized a commitment to excellence in its best research universities, such as the University of California, Berkeley (Douglass 2010). 
Clark Kerr, the architect of the Master Plan, had a vision of the key characteristics for the system's research universities; and these elements are central to the University of California, Berkeley, one of the world's best universities. First, the internal governance of the university is mainly in the hands of the professors; key decisions concerning academic policy and direction, even if initiated by administrators, receive inputs from the academics. This concept of shared governance is central to the idea of the university. The Berkeley campus is rigorously meritocratic in everything that it doesappointment and promotion of faculty, student admissions, and other aspects. Research and teaching are intertwined, but research has the upper hand. Academic freedom is a central value of the academic community. The university has, from the beginning, been engaged with society-particularly with the state of California. The service mission of the university has always been of central importance (Kerr 2001).

Similar to the California model, the academic system in developing countries needs to clearly differentiate the missions in the postsecondary system and to organize institutions in a rational way. Once this is accomplished, appropriate patterns of funding, realistic teaching arrangements, administrative arrangements, and other key elements of institutions will need to be organized and then implemented. Enduring that the rapidly expanding private higher education sector is to some extent integrated into the system will also be necessary. 
The fact is that few if any developing countries have a differentiated academic system in place; and this central organizational requirement remains a key task. Without an appropriate system - the characteristics of each system will vary according to national requirements-research universities cannot fully flourish. These institutions must be clearly identified and supported. There must be arrangements so that the number of research universities will be sufficiently limited so that funding is available for them and that other resources, such as well-qualified academics, are not spread too thinly.

\section{COMMUNICATIONS AND NETWORKS}

Communications and networking are key responsibilities of the research university. Not only do they sit at the top of an academic hierarchy in their own countries and thus have a central role in facilitating communications in the national academic system, but they are also the means that a national academic system needs to communicate with the global knowledge network. Thus, communications are a central element of the research university.

The communication of knowledge is-surprisingly, in the age of the Internet-rather centralized. While it is possible for anyone to communicate globally so long as Internet access is available, access to information is easier than ever in history. In this respect, knowledge has become democratized.

Yet, there is a hierarchy of knowledge; and science and scholarship are built predominantly on the legitimized scientific and scholarly knowledge, 
which is published in key journals and is controlled by gatekeepers in the disciplines. The central knowledge networks in the disciplines are controlled, not surprisingly, by scholars in research universities, mainly in the key knowledge centers worldwide. The research universities of the developing countries are part of this nexus and have access to these networks. Research universities worldwide participate in a range of communications modes, which provide access to the latest trends in science and scholarship, and permit informal communication with colleagues worldwide.

While academics at other less-renowned universities can partake of global scientific knowledge, they are at a significant disadvantage for participating directly in academic dialogue. Research university faculty, with more direct links to colleagues worldwide and better access to informal scholarly and scientific networks, find direct communication easier. Thus, research universities tend to be the point of international knowledge access to global academic systems and are the means that knowledge from developing countries is disseminated to the wider global knowledge network.

Much has been said about the "democratization of science" and the new era of global sharing of knowledge. While this is to some extent the case, it might be more appropriate to label the current situation as the "anarchy of science." Thus, there is an overload of information available coming from many sources and few ways of assessing the value or validity of much of the huge array of 
information. Anarchy makes the established networks in some ways even more powerful-and necessary for determining what is useful knowledge.

\section{Journals}

Despite the expansion of open access and the ubiquity of the Internet, traditional journals remain central to research and dissemination. Indeed, they may be even more important precisely because of the "democratization" of science. The established journal system provides a relatively reliable way of ensuring quality. The traditional journals provide reliable quality control through the external review system: All submissions are evaluated by academic editors and submitted "blind" to external evaluators. Most top journals in any discipline accept only a small proportion of the submissions - some as few as 2 percent. Most disciplines and interdisciplinary and professional fields have a well-known and often informal hierarchy of journals. Further, agencies that monitor journal impact and usage-such as Thompson Reuters' Science Citation Index, Social Science Citation Index, and Arts and Humanities Citation Index-are increasingly important monitors of the most influential publications and authors.

These arbiters of quality and impact are located in the academic centers and do not pay adequate attention to publications from developing countries. In addition, journal publishers, editors, editorial boards, and reviewers are mainly located in the academic centers; they are not significantly concerned with research or academic issues relating to developing countries. Many of the top 
journals are published by multinational publishing conglomerates, such as Elsevier and Springer, which have imposed very high subscription fees-in many cases beyond the capacity of developing country universities to afford purchasing. Even with some special discounts that are offered, the cost of information access is often problematical.

Journal editors, and most authors and reviewers, are located in research universities, further strengthening the roles of these institutions. The research universities, especially in developing countries, are the centers of knowledge communication.

\section{Libraries}

Research university libraries also have responsibility for databases and electronic resources, as well as books and journals. In developing countries, very few libraries have the resources to keep up with current information flows. Their budgets, although often inadequate, support access to global knowledge; and library and information technology staff members provide services that are unavailable elsewhere. This means that the research universities have a special responsibility to ensure that relevant information is made available to the broader academic community. The role of libraries, often overlooked in the Internet age, remains of central importance-precisely because libraries have become not only repositories of books and journals but also the main information technology providers for the university and academic community. 


\section{The "Invisible College"}

Informal communities of scholars and scientists are crucial to science (Crane 1972). These invisible colleges exist in every field and are often the base of innovative interdisciplinary work. In the age of the Internet, these communities have, to some extent, become virtual - with communication taking place though the Internet. Research universities are typically the centers for knowledge communities of all kinds. Internationally, scholars tend to recognize peers at research universities, as equal partners. Regionally and within countries, the research universities are centers of these informal communities of scientists and scholars.

\section{Conferences and Professional Organizations}

National, regional, and international conferences are parts of the nexus of communication for science. Virtual communication has by no means meant a decline in conferences-indeed, face-to-face meeting remains necessary. The conferences sponsored by professional academic organizations, as well as other scholarly and scientific meetings, provide opportunities to share ideas and research and, to build community, are very much linked to research universities. Academics from research universities are most active in these organizations and more often have funds available to send faculty members to conferences. Scholarly organizations also legitimize particular kinds of research, as well as 
providing visibility to scientists and scholars most active in their fields. Developing countries are at a significant disadvantage because scholarly and scientific organizations are controlled by scholars at the top universities in the center countries, and their conferences take place for the most part in Europe or North America.

\section{The Internet}

The Internet is, of course, the major element in the communications revolution of the past several decades and will continue to influence in higher education in many ways into the future. Research universities are at the core of the Internet revolution. In developing countries, research universities are likely to obtain the fastest Internet connections, making it easier to communicate and access data. Likewise, until quite recently and to some extent even now, Internet access has not been entirely reliable in many developing country universities. Research universities not only have the "hardware" such as equipment and fast connectivity but also the "software"-personnel skilled in information technology and of course an academic community active in research and communications.

Communications and networking are at the center of the research university mission but are not frequently discussed. Worldwide, these issues are central to the mission and unique contributions of research universities, which no other institutions can undertake. 


\section{REPOSITORIES OF KNOWLEDGE}

Research universities are centers of knowledge of all kinds. Their academic staff are often the most knowledgeable scholars and researchers in the country, on perhaps every topic. Professors not only do basic and applied research but also provide information to society through consulting, informal advice, and often through direct public service. It is not surprising that research university academics are often called on to serve as government advisers, ministers, or even heads of government during crises. Expertise on economics, the environment, agriculture, or almost any topic is often useful to the broader society. This service is particularly valuable in developing countries, where expertise outside of the universities in many fields is limited. Sharing expertise is a service to the broader society and a way of building valuable networks with government, industry, and civil society. The research universities are the main institutions with the type of knowledge and experience that will be useful-and the interdisciplinary depth that may aid in solving complex problems.

Research universities are very often among the main repositories of historical and cultural information and artifacts. Research universities sometimes sponsor museums and other cultural institutions and are able to manage them in countries that limited capacities in these fields. These museums are in many different fields-including, art, antiquities, science, medicine, culture, and others. Libraries at research universities often house special collections of historical 
manuscripts and artifacts, providing a significant historical resource for developing countries. In one case, the national university operates the main astronomical observatory for the country.

Research university libraries are often the largest collections of books and other research materials and, in a few cases, are designated as the national library. The resources in these libraries constitute the main research collections for the country and are used not only by faculty and students but by others for research. Now, digital resources are also stored by research universities, and in many cases, these universities are responsible for digitizing valuable historical and cultural artifacts for society.

The research universities typically have the largest and best-equipped scientific laboratories in many developing countries and thus provide a valuable resource for the scientific community in the nation. In some cases, university facilities serve as research facilities for other institutions, including government agencies.

Often, the role and the responsibility of research universities as repositories of knowledge are ignored in discussions of higher education - and in budgetary allocations for them.

\section{Research Universities as CRITICAL CENTERS}

The academic community in research universities, both faculty and students, often serve as social and cultural critics in their societies. Although sometimes 
not appreciated by government leaders, academic intellectuals provide a necessary voice in the analysis of societal trends. Faculty members frequently write op-ed articles in the press, appear on television, increasingly write blogs, and otherwise participate in the electronic media. University academics have significant advantages. They are well educated in their fields of research, can speak with authority, and are articulate and able to effectively present their views in print and on television. Academics hold positions of respect and prestige in their societies - and the public will often take their views seriously. Universities, with some exceptions, offer reasonable protections of academic freedom; and even in countries with limits on freedom of expression, academic staff have more autonomy to speak and write than may be the case for others. Because of their knowledge and prestige, academics can often get access to the media for their views.

Students sometimes express their social critiques in different ways - very often through political organization and activism. In many developing countries, there are strong traditions of campus activism. Student dissent has expressed itself on many themes and topics, including opposition to governments, criticism of specific policies, demands for higher education reform, and others (Altbach 1989). In some cases in developing countries, students have been instrumental in toppling governments, while in others they have focused attention on societal problems. Students have also politicized universities, created social tensions; and 
on some occasions their activism has stimulated governments to close universities entirely, sometimes for extended periods of time.

Academics, and occasionally universities, establish journals and other publications that contribute to intellectual and political dialogue. In keeping with current technology, they also develop Web sites, twitter feeds, and blog networks. The research universities are especially active in these areas because their employees have more available time and are accustomed to writing for an external audience.

The research university academic communities have the motivation, knowledge, and commitment to participate in cultural, political, and social dialogue in society. They also have access to participate in the technologies and technical skills. In developing countries, especially, research university academics are among the few constituencies who have these skills. Thus, there are fewer other groups in society who are able to take part in critical discourse, than would be found in industrialized societies.

\section{THE GLOBALIZATION OF SCIENCE AND SCHOLARSHIP}

Globalization is both a benefit and a curse to research universities in developing countries (Altbach 2004; Knight 2008). These universities are at the center of global knowledge communication and networks. They funnel new ideas and knowledge into the higher education system and the country as well, and they permit the academic community to participate in international science and 
scholarship. It is possible, in the age of the Internet, for individuals anywhere to take advantage of global knowledge; but the resources and academic community of research universities make international participation easier and more effective. In many countries, research universities may be the only institutions adequately linked to global networks. Thus, research universities provide a twoway street for scientific participation.

At the same time, for many universities, globalization constitutes a threat. The global academic marketplace for professors and students means that the best students and staff can be lured away. Overreliance on international "core" journals for promotion and research criteria may place professors in peripheral research universities at a disadvantage. Globalization tends to favor the "centers" over other universities; it does not necessarily contribute to the democratization of science and scholarship. Thus, globalization is a two-edged sword in higher education.

Science in the 21st century is truly global in scope. Research results are immediately available worldwide through the Internet. Scientific journals are circulated internationally, and academics contribute to the same publications. Methodologies and scientific norms are used worldwide more than ever before. Scientific equipment, ever more sophisticated and expensive, is available everywhere. Moreover, and there is pressure for research universities to have the most modern laboratories, if they wish to participate in global scientific research. Further, research is increasingly competitive, with researchers and universities 
rushing to present results and patent or license potentially useful discoveries or inventions. Science, in short, has become a "high-stakes" and intensely competitive international endeavor. Entry into advanced scientific research is expensive, as is maintaining a competitive edge.

The challenge consists not only of laboratories and infrastructures but also the definitions and methodologies of science and scholarship. Scientific globalization means that participants are linked to the norms of the disciplines and of scholarship that are established by the leaders of research, located in the major universities in the United States and other Western nations. The methods used in funded research and presented in the main scientific journals tend to dominate world science. Further, the themes and subject areas of interest to leading scientists and institutions may not be relevant to universities at the periphery. Involvement in world science means, in general, adherence to established research paradigms and themes.

The high cost of science creates serious problems for academic institutions, without a long tradition of research and the required infrastructures and equipment. It is no longer sufficient to build an infrastructure that permits research on local or regional themes, if a university wishes to join the "big leagues." Universities that wish to be considered research oriented need to participate in the international scientific network and compete with institutions and scientists worldwide. The costs of joining the league of research universities is an especially serious concern for developing countries, with funding problems 
and no experience of building such institutions. Small academic institutions in both larger countries and small industrialized countries, seeking to transform themselves into research universities, face similar challenges. The world of global science is expensive to join, and sustaining participation is also costly.

The paradox of global science is similar to globalization in general. Globalization-through information technology, better communications, the worldwide circulation of highly trained personnel, and other factors-permits everyone to participate in the global marketplace of science, scholarship, and ideas. At the same time, globalization subjects all participants to the pressures of an unequal global knowledge system, dominated by the wealthy universities, and imposes the norms and values of those institutions on all (Altbach 1987).

\section{INTERNATIONALIZATION AND THE RESEARCH UNIVERSITY}

Research universities are typically the most internationalized postsecondary institutions. They are the point of contact with the global knowledge community through their research and the involvement of their academic staff in international activities. Research universities see themselves as part of a global academic community and develop the infrastructures to support international activities. They are more likely to have administrative staff to support international activities, than other academic institutions, and are more able to support foreign students and faculty on their campuses (Altbach and Knight 2007). 
Research universities frequently hire faculty internationally and, as a result, have professors who can assist international linkages. Research projects may have an international dimension, both in terms of methodological and substantive foci and also research groups. Research university faculty members, than academics generally, are more likely to publish internationally, to work with colleagues in other countries, and to participate in international conferences. This means that they are better networked and more capable to participate in international activities.

Research universities are logical partners with prominent overseas universities. Top foreign institutions in the industrialized world typically prefer to link with peer institutions overseas. The research universities tend to be the best-known and most highly ranked institutions in their countries.

The research universities often have strong international and area studies programs, thus relevant courses in some foreign languages and cultures, and in some cases center and institutes focusing on different parts of the world. They are, furthermore, able to offer programs for international students, focusing on the language and culture of their country - often a strong attraction for foreign partners.

In some cases, internationalization involves working with foreign institutions on joint-degree programs, branch campuses, and other kinds of academic programs. Research universities are in a favorable position to choose 
among the best overseas partners and to offer the best-quality collaborative arrangements.

Research universities sometimes have a strategy for building international programs and linking with overseas universities, building their international competence, and creating an international presence. While such international plans are typically carried out by universities in the industrialized nations, developing country research universities are increasingly creating international plans, as well. Top universities in China, for example, generally have developed internationalization strategies, and this trend is expanding to other developing and middle-income countries.

Research universities in the north have a special responsibility to link with their counterparts in the south. A community of research-intensive universities can provide benefits to all participants. Academic institutions in the north can assist in developing infrastructures, model best practices of academic management, and provide opportunities for mentorship. Universities in the south can provide sources for collaborative research and teaching. Funds allocated for joint research, training programs, and related initiatives can benefit both sides. Of course, such collaboration must be undertaken in a spirit of equality and shared responsibility. All can benefit from the internationalization of the global community of research universities. 


\section{The Dilemma of LANGUAGe}

Language is always a complex issue for research universities in developing countries (Altbach 2007b). These universities must, without exception, have appropriate competence in the global scientific language-English. Without a reasonably high level of skill in English by both academic staff and students, universities cannot function effectively in the global knowledge network. Many universities in developing countries demand English-language competence by entering students.

Universities in the industrialized nations, even in countries that do not use English as the language of instruction in the universities, expect that their international academic relations will take place in English; and increasingly they are offering some courses and often entire degree programs in English. Generally, when they are establishing joint degrees or branches, the expectation is that the programs will be offered in English.

A significant number of developing country research universities provide all or most of their instruction in English, while others are increasingly emphasizing English as the medium of academic discourse. South Asian universities function largely in English - based on their British colonial tradition. In sub-Saharan Africa, all of the universities operate in a European languagethe largest number in English, while others use French, Portuguese, or Afrikaans. English is gaining ground, as South African universities gradually move away from Afrikaans; and even Rwanda has shifted from French to English. An 
interesting case is Malaysia, which moved from English to Bahasa Malaysia, and now is restoring English in some universities.

While most developing countries are placing more emphasis on English, this is not universally the case. While Francophone and Lusophone Africa, for example, are largely remaining loyal to these languages, these countries are global exceptions. Instruction in Latin American countries remains in Spanish or Portuguese, although English is becoming more prominent.

English, however, is increasingly used as a language of instruction in some courses and programs. Top Chinese research universities, for example, are increasingly offering courses in all disciplines in English for Chinese students.

Professors are encouraged, and, sometimes, required to publish their research in English, preferably in journals recognized by the international corporations that measure impact and usage. This places academics in developing countries at a significant disadvantage, not only due to language fluency issues but because the methodologies and peer-review evaluators are mainly in the academic centers and may not be sympathetic to the issues of concern to developing country authors.

Focusing increasingly on English also means that scientific, academic, and cultural discourse in local languages receives less attention, and this may well result in deemphasizing local knowledge and research on issues that are relevant to the country. Language is not only a medium for communication; it is also an important part of a culture and tradition (Lillis and Curry 2010). Developing 
country research universities requires an appropriate balance between international involvement and local relevance.

Language choice is an extraordinarily complex matter globally, and particularly in developing countries. In some countries, Saudi Arabia for example, the hard sciences tend to be taught in English while the social sciences and humanities use Arabic. In some cases, research universities use English while other universities may be in the local language. There are few, if any, examples of countries moving away from an international language to a local language. The costs and benefits of language choices must be carefully assessed.

\section{The Academic Profession}

The professoriate is central to higher education. Research universities rely especially on the quality and focus of the academic profession, and current developments relating to the professoriate worldwide are not favorable for either the profession or for research universities (Altbach 2003). Research universities require academic staff with the highest-possible qualifications - doctoral degrees from reputable universities. This seemingly obvious statement is necessary because the majority of academic staff in developing countries do not hold a doctorate. While there are no reliable statistics available, only a minority of academics in developing countries hold a doctorate-although the proportion in research universities in much higher. In China, for example, almost all research university staff have earned doctorates (Ma and Wen 2013). 
Research universities require full-time professors, scholars, and scientists, who devote their full professional attention to teaching and research at the universities. Without a large majority of full-time academic staff, it is simply impossible to build a cadre to form a committed and effective professoriate. Not only required to fulfill the core functions of the university, full-time faculty also need to participate in governance and management, because research universities need a high degree of autonomy and faculty governance. The lack of full-time faculty is one central reason most Latin American countries have failed to build research universities.

Along with full-time commitment, salaries must be sufficient to support a middle-class lifestyle (Altbach, et al. 2012). While they need not be paid salaries similar to those of colleagues in the most highly remunerated universities internationally, professors must be solid members of the middle class in their country. Frequently, full-time professors generate a significant part of their incomes, through consulting, moonlighting at other institutions or, at some universities, taking on extra teaching loads in fee-producing programs. These arrangements detract from the core functions of the professoriate and make full academic productivity difficult to maintain. In some disciplines, consulting work, applied research for industry, and other links with external agencies may provide useful synergies for academic work. Yet, in many countries, outside work and dependence on additional income are deleterious to the research university. As problematic, academic salaries, overall, have stagnated 
worldwide-at the same time that remuneration for similarly educated professionals outside universities has increased in some countries quite dramatically. In order to attract the "best and brightest" to academe, salaries must be competitive.

Teaching responsibilities must be sufficiently limited, to allow time and energy for research. In the United States, the standard teaching load in most research universities regards two courses per semester or four per academic year. In some scientific fields, even less teaching is expected. Similar teaching loads are common in Europe. In many developing countries, much more teaching is required, leaving little time for research. The most-active, research-focused professors in the United States undertake a significant part of their teaching in graduate (postbaccalaureate) programs, which helps to link teaching with research and increases productivity. In European countries, with doctoral programs mainly focused on research, professors are given sufficient time for doctoral supervision and mentoring (Nerad and Heggelund 2008).

The academic profession must have a career ladder that permits talented professors to be promoted up the ranks of the profession on the basis of their performance, the quality of their work, and a salary structure determined by performance. In many countries, an initial full-time appointment is tantamount to a permanent job. In much of the world, promotion up the academic ranks is largely a matter of seniority and not of demonstrated performance in teaching and research. In the majority of countries, academic salaries are determined by 
seniority, rank, and, in some places, discipline - rather than by job performance. This is especially true for countries where academics are considered civil servants - mainly in western Europe (Enders 2001; Altbach, et al. 2012). Civil service status provides strong guarantees of permanent employment but seldom measures productivity as an element of promotion.

The challenge is to link reasonable guarantees of long-term employment, both as a means of ensuring academic freedom and as a way of providing employment security and institutional loyalty. The American tenure-track system, although criticized within the United States, may be closest to this goal (Chait 2002). It provides initial probationary appointments with a series of rigorous evaluations that, if passed, lead to a permanent (tenured) appointment after six years. Further promotion, from the rank of associate to full professor, is also merit based and depends on a rigorous evaluation. Most American colleges and universities follow this pattern, although the research universities have the most stringent evaluations. Increasingly, US universities have also instituted "post-tenure review," so that productivity is measured following the award of tenure. Typically, salary raises are given, based on performance as well as seniority.

Even in the United States, the academic profession is threatened-from the perspective of the research universities. The two most serious problems are the growth of a part-time academic workforce and the relatively new category of non-tenure-track, full-time appointments. Half of the new positions at US 
colleges and universities are in these categories, although at research universities the proportion of tenure-track positions is higher (Schuster and Finkelstein 2006).

The academic profession is central to the success of the university, everywhere. A research university requires a special type of professor-highly trained, committed to research and scholarship, and motivated by intellectual curiosity. Full-time commitment and adequate remuneration constitute other necessities. A career path that requires excellence and at the same time offers both academic freedom and job security is also required. Academics at research universities need both the time to engage in creative research and the facilities and infrastructures to make this research possible. For developing countries, their characteritics are especially important as research universities seek to build themselves to world-class status.

\section{Present Circumstances}

To paraphrase Charles Dickens, these are the best of times and the worst of times for research universities. There is widespread recognition of the importance of the research university for almost every country. The salience of international academic connections and the role of research in the global knowledge economy are understood as central to sustainable economic growth and stability. However, many countries do not recognize the complexity of and the resources needed for building and sustaining research universities (Salmi 2009). 
The early 21st century is a period of emerging research universities in countries, where they have not existed before, and the strengthening of current institutions. It is also a time of the internationalization of a research university.

It is possible to outline some of the characteristics of successful research universities.

- Virtually all-successful research universities are a part of a differentiated academic system, where they stand at the top of an academic hierarchy and receive appropriate support for their mission.

- Research universities, except in the United States and Japan and a small number of mostly Roman Catholic institutions in Latin America, are overwhelmingly public institutions. The private sector can seldom support a research university, although some private universities are emerging with the goal of focusing research in countries - such as Turkey, India, and ones in Latin America.

- Research universities are most successful in regions with little or no competition from nonuniversity research institutes or with strong ties between the universities and such institutes. The "academy of science" system in countries such as Russia and China, the Centre National de Recherche Scientifique in France, and some other models of research institutes generally lack such connections to universities. There are efforts in some countries to better integrate research institutes and the top 
universities, in some cases merging them; and this will, undoubtedly, strengthen the universities.

- Research universities are expensive institutions. They require more funding than other universities - to attract the best staff and students and to provide the infrastructure necessary for top research and teaching. The "cost per student" is inevitably higher than the average across an entire higher education system. Adequate salaries for faculty, well-equipped libraries and laboratories, and scholarship assistance for bright but needy students are examples of the expenditures required.

- Research universities must have adequate and sustained budgets; they cannot succeed on the basis of inadequate funding or severe budgetary fluctuation overtime. Research universities require steady funding, particularly as they get established but also generally.

- At the same time, research universities have the potential for significant income generation. Students are often willing to pay higher tuition and fees at these institutions-because of the prestige attached to a degree from them as well as the high quality of academic programs and access to the best professors. Research universities also generate intellectual property and other discoveries and innovations that have value in the marketplace. In addition, in some countries, research universities, in part because of their prestige, can generate philanthropic gifts for helping to build an endowment for the university. 
- Research universities require physical facilities commensurate with their missions, and this means expensive libraries and laboratories. Sophisticated information technology is also required. All of this is not inexpensive. The infrastructures of research universities are both complex and expensive. Not only do they need to be built but must also be maintained and periodically upgraded.

- Research universities require appropriate autonomy to shape their own programs and practices. The balance between autonomy and accountability in developing countries may be complicated.

- Academic freedom is a requirement for all postsecondary institutions but especially important for research universities.

The requirements of the research university are complex. They are physical and human but also contain ideas and orientations relating to academic work.

\section{CONCLUSION}

Research universities in developing countries are situated at the top of an academic and intellectual hierarchy and are central to the success of any modern knowledge-based economy. All developing countries need these institutions to participate in the globalized environment of higher education. Thus, understanding the characteristics of the research university and building the infrastructures and the intellectual environment needed for successful research universities is a top priority. 
AUTHOR'S NOTE: This paper builds on analysis in Altbach 2009 and Altbach 2011. Thanks to Dr. Ahmad Hasnah and participants in the Boston IHERD conference for comments.

\section{REFERENCES}

Altbach, Philip G. 1987. The knowledge context: Comparative perspectives on the distribution of knowledge. Albany: State Univ. of New York Press.

- - - ed. 1989. Student political activism: An international reference handbook. New York: Greenwood.

- - - ed. 2003. The decline of the guru: The academic profession in developing and middle-income countries. New York: Palgrave.

- - - 2004. Globalization and the university: Myths and realities in an unequal world. Tertiary Education and Management 10: 3-25.

- - . 2007a. Empires of knowledge and development. In World class worldwide:

Transforming research universities in Asia and Latin America, ed. Philip G. Altbach and Jorge Balán, 1-28. Baltimore: Johns Hopkins Univ. Press.

$---.2007 \mathrm{~b}$. The imperial tongue: English as the dominating academic language.

Economic and Political Weekly, September 8: 3608-11.

- - - 2009. Peripheries and centers: Research universities in developing countries.

Asia Pacific Education Review 10: 15-27.

- - - 2011. The past, present, and future of the research university. In The road to academic excellence: The making of world-class research universities, ed. Philip G. Altbach and Jamil Salmi, 11-30. Washington, DC: World Bank. 
Altbach, Philip G., and Jane Knight. 2007. The internationalization of higher education: Motivations and realities. Journal of Studies in International Education 11, no. 3-4: 274-90.

Altbach, Philip G., Liz Reisberg, Maria Yudkevich, Gregory Androushchak, and Iván F. Pacheco, eds. 2012. Paying the professoriate: A global comparison

Chait, R. P., ed. 2002. The questions of tenure. Cambridge, MA: Harvard Univ. Press.

Crane, Diana. 1972. Invisible colleges: Diffusion of knowledge in scientific communities. Chicago: Univ. of Chicago Press.

Douglass, John Aubrey. 2010. From chaos to order and back? A revisionist reflection on the California Master Plan for higher education@50 and thoughts about its future. Berkeley, CA: Center for Studies in Higher Education.

Enders, J., ed. 2001. Academic staff in Europe: Changing contexts and conditions. Westport, CT: Greenwood.

Hazelkorn, Ellen. 2011. Rankings and the reshaping of higher education: The battle for world-class excellence. Houndsmill, UK: Palgrave Macmillan.

Kerr, C. 2001. The uses of the university. Cambridge, MA: Harvard Univ. Press.

Knight, Jane. 2008. Higher education in turmoil: The changing world of internationalization. Rotterdam, Netherlands: Sense.

Lillis, Theresa, and Mary Jane Curry. 2010. Academic writing in a global context: The politics and practices of publishing in English. New York: Routledge.

Ma, Wanhua, and Wen Jianbo. 2013. The Chinese academic profession: New realities. In The Global Future of Higher Education and the Academic Profession: The BRICs and the United States, ed. Philip G. Altbach, Gregory Androushchak, Yaroslav Kuzminov, Liz Reisberg, and Maria Yudkevich. New York: Palgrave Macmillan. 
Mohrman, Kathryn, Wanhua Ma, and David Baker. 2008. The research university in transition: The emerging global model. Higher Education Policy 21: 5-27.

Nerad, Maresi, and Mimi Heggelund, eds. 2008. Towards a global PhD? Forces and forms in doctoral education worldwide. Seattle: Univ. of Washington Press.

Rhoten, Diana, and Craig Calhoun. 2011. Knowledge matters: The public mission of the research university. New York: Columbia Univ. Press.

Salmi, Jamil. 2009. The challenge of establishing world-class universities. Washington, DC: World Bank.

Schuster, J. H., and M. J. Finkelstein. 2006. The American faculty: The restructuring of academic work and careers. Baltimore: Johns Hopkins Univ. Press. 